\title{
Peri-operative management of anti-platelet agents and anti-thrombotic agents in geriatric patients undergoing semi-urgent hip fracture surgery
}

\author{
H. H. Ho $・$ T. W. Lau $\cdot$ F. Leung $\cdot$ H-F. Tse $\cdot$ C-W. Siu
}

Received: 18 August 2010 / Accepted: 14 September 2010

(C) The Author(s) 2010. This article is published with open access at Springerlink.com

\begin{abstract}
Hip fractures are common events in the geriatric population and are often associated with significant morbidity and mortality. Over the coming decades, the size of the greying population is forecast to increase and hence, the annual incidence of hip fracture is expected to rise substantially. Several studies have shown that hip fracture surgery performed within 24 to $48 \mathrm{~h}$ of hospitalisation significantly reduces mortality. Medical specialists including cardiologists are often involved in the care of these geriatric patients as most of them have comorbid conditions that must be managed concomitantly with their fracture. Cardiovascular and thromboembolic complications are among some of the commonest adverse events that could be experienced by these elderly patients during hospitalisation. We review in this article the current recommendations and controversies on the perioperative management of anti-platelet agents and anti-
\end{abstract}

H. H. Ho $(\bowtie)$

Department of Cardiology, Tan Tock Seng Hospital,

11, Jalan Tan Tock Seng,

Singapore, Singapore 308433

e-mail: hokai_wah@yahoo.com

T. W. Lau $\cdot$ H.-F. Tse $\cdot$ C.-W. Siu

Cardiology Division, Department of Medicine,

Queen Mary Hospital, University of Hong Kong,

Hong Kong, SAR, China

T. W. Lau $\cdot$ H.-F. Tse $\cdot$ C.-W. Siu

Research Center of Heart, Brain, Hormone and Healthy Aging,

Li Ka Shing Faculty of Medicine, University of Hong Kong,

Hong Kong, SAR, China

F. Leung

Department of Orthopaedics and Traumatology,

Li Ka Shing Faculty of Medicine, University of Hong Kong,

Hong Kong, SAR, China thrombotic agents in geriatric patients undergoing semiurgent hip fracture surgery.

Keyword Osteoporosis

\section{Introduction}

Hip fractures are common events in the geriatric population and are often associated with significant morbidity and mortality. Mortality from hip fracture [1] approaches $20 \%$ or more at 1 year. Of those who survive to 6 months [2], only $60 \%$ recover their prefracture walking ability. Approximately $25 \%$ of the individuals [3] who were living independently before the fracture require long-term nursing care.

Hip fracture is considered a surgical disease; thus, prompt surgical correction is necessary for preservation of function. The surgery [4] itself carries a $4 \%$ mortality risk. Medical specialists [5] including cardiologists are often involved in the care of these geriatric patients as most of them have comorbid conditions that must be managed concomitantly with their fracture. Cardiovascular and thromboembolic complications are among some of the commonest adverse events that could be experienced by these elderly patients during hospitalisation besides infection, delirium, etc., which could potentially contribute to the risk of functional decline, nursing home admission and mortality.

This review article will focus on three parts:

1. periprocedural management of patients with hip fracture, who happened to be taking anti-platelet agents (single or dual) for underlying coronary artery disease with particular emphasis on those who received coronary stents, 
2. general overview of the thromboembolic prophylaxis in geriatric patients undergoing semi-urgent hip fracture surgery,

3. discussion on regional anaesthesia.

Timing of surgical intervention for hip fracture

Hip fracture surgery should be performed within 24 to $48 \mathrm{~h}$ of hospitalisation for patients who are medically stable and without significant comorbidities. Most studies [6-10] have shown that surgical repair within this timeframe significantly reduces mortality.

For patients with active comorbid medical conditions, such as unstable angina, congestive heart failure, chronic obstructive pulmonary disease, etc., it is prudent to delay the operation to as long as $72 \mathrm{~h}$ and optimise their medical conditions first.

\section{Anti-platelet agents}

The two most common anti-platelet agents encountered in clinical practice are aspirin and thienopyridines (e.g., clopidogrel and ticlopidine). They are usually taken by patients with atherothrombotic disease. Some patients may be taking dual anti-platelet therapy due to implantation of coronary artery stents, acute coronary syndrome and cerebrovascular disease. Anti-platelet agents are often stopped before elective surgery in order to reduce procedure-related bleeding. The decision to discontinue anti-platelet agents before hip fracture surgery should take into account the potential risk of stopping the medications, and consultation with the patient's cardiologist or neurologist should be considered prior to any decision.

\section{Aspirin}

A meta-analysis [11] of ten orthopaedic trauma trials found that aspirin significantly reduced the rate of deep venous thrombosis and pulmonary embolism compared with placebo. However, this reduction was significantly less when compared with other agents like warfarin and lowmolecular-weight heparin. Hence, aspirin alone provides some although suboptimal protection against thromboembolic events after hip fracture.

For patients with coronary artery stents, non-cardiac surgery increases the risk of stent thrombosis, myocardial infarction and death especially if the patients undergo hip fracture surgery early after stent implantation. Peri-operative or post-operative stent thrombosis is a life-threatening complication for patients with either bare-metal or drug-eluting stents. It is generally recom- mended that for such patients, aspirin must be continued throughout the peri-operative period [12] as it does not appear to increase the risk of significant bleeding after hip fracture surgery.

Thienopyridines

Thienopyridines (e.g., clopidogrel and ticlopidine) are often used in combination with aspirin. Dual anti-platelet therapy is especially important in patients who have undergone coronary stent implantation. For patients with history of coronary stenting who present with hip fracture, it is important to know the date of the last percutaneous coronary intervention and the type of stent put in.

There are limited data regarding the management of patients on dual anti-platelet agents with a recently placed coronary stent who require a semi-urgent hip fracture surgery. Discontinuation of anti-platelet therapy in these patients confers significant morbidity and mortality [13-16] because stent endothelialisation may not be complete at the time of surgery and combined with prothrombotic state induced by surgery increases the risk of acute peri-operative stent thrombosis and myocardial infarction.

There is also little evidence $[12,17]$ to define the true impact of continuing thienopyridine on bleeding in noncardiac surgery. When compared with aspirin alone, the combination of clopidogrel and aspirin increases the absolute risk of major bleeding by $0.4-1.0 \%$.

The American College of Cardiology and American Heart Association guidelines [18] recommend that whenever possible, elective or semi-elective procedures should be postponed until the patient has received at least the minimum length of dual anti-platelet therapy depending on whether bare-metal(BMS) or drug-eluting stent(DES) was implanted.

At present, there is no definitive standard of care [19-21] on the optimum peri-operative anti-platelet regimen in patients with coronary stents particularly those with drugeluting stents. As mentioned earlier, aspirin can be continued peri-operatively regardless of whether patient had received BMS or DES. For patients who had BMS implantation at least 4 weeks ago prior to admission or DES implantation at least 12 months ago, the thienopyridine can be stopped if surgical bleeding is a concern.

The clinical delimma comes when we are faced with patients who present with hip fracture and had undergone BMS implantation $<4$ weeks or DES implantation $<12$ months ago. There are three options that can be considered for the anti-platelet regimen. Firstly, one can choose to continue dual anti-platelet therapy [22] throughout the peri-operative period if possible. Secondly, since anti-thrombotic agents (e.g., lowmolecular-weight heparin) are often used as thromboembolic prophylaxis in hip fracture, one can implement it as bridging 
therapy [21] to substitute for dual anti-platelet therapy. Although success with bridging therapy has been reported, prospective studies are necessary to validate it as a viable management strategy. Recent studies [23] have recommended bridging therapy with glycoprotein IIb/IIIa inhibitors primarily for those who have not completed dual anti-platelet therapy and in patients whose stent complexities and comorbidities significantly increase their risk for developing catastrophic stent thrombosis. The final option is discontinue thienopyridine preoperatively and following the hip fracture surgery, the thienopyridine should be restarted [24], with or without a loading dose, as soon as it is deemed safe.

Primary percutaneous coronary intervention is the definitive treatment for peri-operative stent thrombosis as administration of thrombolytic is contraindicated in patients with recent surgery. Hence, for patients with previous coronary stenting, hip fracture surgery should ideally be performed in institutions where $24 \mathrm{~h}$ interventional cardiology services are available to provide emergent intervention if the need arises.

\section{Anti-thrombotic agents for thromboembolic prophylaxis}

Venous thromboembolism is one of the leading causes of peri-operative morbidity and mortality in patients with hip fracture. In the absence of thromboembolic prophylaxis, the prevalence of venography-detected proximal deep venous thrombosis was $27 \%$ in patients who had undergone hip fracture surgery [25]. The incidence of fatal pulmonary embolism ranges from $0.4 \%$ to $7.5 \%$ of patients within 3 months of hip fracture surgery.

Although thromboembolic prophylaxis is a routine aspect of care in patients with hip fracture, there is no clear-cut guideline regarding the optimal agent, the timing and duration of prophylaxis. Whether to initiate thromboembolic prophylaxis before or immediately after surgery is still unclear.

Deep venous thrombosis may begin as early as the time of hip fracture. Until more definitive data is available, it is reasonable to initiate anti-thrombotic therapy as soon as patient is admitted into hospital. The American College of Chest Physicians (ACCP)guidelines [26] recommend the use of three agents for thromboembolic prophylaxis namely fondaparinux, unfractionated heparin (UFH) and lowmolecular-weight heparin (LMWH).

\section{Fondaparinux}

Fondaparinux is a synthetic highly sulfated pentasaccharide that binds to anti-thrombin with a higher affinity than heparin and is recommended as an option for first-line prophylactic therapy.
In the largest randomised trial [27] of thromboprophylactic therapy to prevent venous thromboembolism in patients with hip fracture, the incidence of venous thromboembolism $(8.3 \%$ versus $19.1 \%)$ was significantly lower in the group of patients receiving subcutaneous fondaparinux $2.5 \mathrm{mg}$ once daily when compared to those receiving subcutaneous enoxaparin $40 \mathrm{mg}$ daily. Despite superior efficacy, its main drawback is the high cost which hampers its wide clinical application.

\section{Unfractionated heparin}

Low-dose UFH $(5,000$ U subcutaneous administration twice daily) has been the agent [28] most frequently studied for thromboembolic prophylaxis. Several studies have shown that UFH heparin significantly reduced the risk of deep venous thrombosis when compared to placebo in patients undergoing hip fracture surgery with a slight increase risk of post-operative bleeding.

\section{Low-molecular-weight heparin}

LMWH confers similar reduction in the risk of thromboembolic disease when compared to low-dose UFH. A systematic review [29] of 31 trials involving 3,000 patients with hip fracture could not determine the superiority of either form of heparin.

Recommended regimens for enoxaparin are $30 \mathrm{mg}$ subcutaneously every $12 \mathrm{~h}$ or $40 \mathrm{mg}$ once daily. LMWH are cleared principally by the renal route and their half-life is prolonged in patients with renal failure. The dosage of enoxaparin must be adjusted for elderly patients who often have renal impairment. Studies of LMWH have reported that the incidence of post-operative bleeding is similar to bleeding rates observed with UFH.

However, the incidence of heparin-induced thrombocytopenia is lower with LMWH than UFH.

\section{Duration of thromboembolic prophylaxis}

At present, it seems reasonable to continue prophylaxis until the patient is fully ambulatory. Prophylaxis may be extended [26] for a longer duration for high-risk patients, e.g., those who developed prolonged immobility, previous history of venous thromboembolism, etc.

\section{New agents}

Oral direct thrombin inhibitors are emerging as new agents for anti-thrombotic therapy in patients with risk of thromboembolism. Dabigatran [30] is currently being investigated for prophylaxis of deep venous thrombosis and thromboembolic disease in patients undergoing hip replacement surgery. 


\section{Regional anaesthesia}

Patients with hip fracture can be put under general or regional anaesthesia for the corrective surgery. Certain precautions pertaining to regional anaesthesia need to be taken into account with regards to anti-platelet and antithrombotic agents.

In patients with coronary artery stents, the use of regional anaesthesia must be carefully considered. Studies $[31,32]$ have shown that regional anaesthesia attenuates the hypercoagulable peri-operative state and also provides antiplatelet effects by decreasing platelet aggregation. Stent thrombosis may occur in higher-risk patients if anti-platelet agents are discontinued.

The American Society of Regional Anaesthesia (ASRA) 2003 guidelines [33] consider the use of thienopyridines and dual anti-platelet agents as relative contraindications to neuraxial anaesthesia or peripheral nerve blockade in non-compressible regions that cannot be observed for bleeding. The actual risk of spinal hematoma is unknown in this subgroup of patients, and there have been case reports of this adverse complication in the presence of anti-platelet and anti-thrombotic agents. Although the ASRA recommends discontinuing clopidogrel 7 days and ticlopidine 14 days before regional anaesthesia, variances from their recommendation may be acceptable based on the clinical judgement of the responsible anaesthesiologist.

Aspirin alone does not appear to increase the risk of spinal hematoma. However, concurrent use [34, 35] of UFH or LMWH increases the risk of bleeding and spinal hematoma in the presence of aspirin monotherapy. In patients receiving LMWH alone, the current ASRA guidelines recommend delaying neuraxial blockade at least $10-12 \mathrm{~h}$ after the last LMWH dose. LMWH has also been reported to cause bleeding/hematoma within the spinal column in patients receiving regional anaesthesia. The United States Food and Drug Administration (FDA) [36] recommend that patients receiving regional anaesthesia who are treated with $\mathrm{LMWH}$ should be monitored frequently for signs and symptoms of neurologic impairment. Current ASRA guidelines [33] recommend removal of epidural catheter $1 \mathrm{~h}$ before administration of UFH and $2 \mathrm{~h}$ before LMWH. The appropriate time interval between catheter removal and clopidogrel administration remains undefined.

\section{Summary and recommendations}

Patients with hip fracture who are medically stable and free of significant comorbidities should undergo surgical correction within 24 to $48 \mathrm{~h}$ in order to obtain the best chance for functional recovery and survival.
For those taking anti-platelet agents, aspirin should be continued throughout the peri-operative period as its benefit outweighs the risk of bleeding. As for patients with history of coronary stenting and taking thienopyridine on top of aspirin, clinical judgement is of utmost importance in balancing the risk/benefit ratio of dual anti-platelet therapy interruption versus continuation. Good communication between the patient's cardiologist, surgeon and anaesthesiologist is essential to achieve a favourable outcome for the patient and to minimise the risk of catastrophic stent thrombosis.

As patients with hip fracture are also prone to venous thromboembolism, thromboembolic prophylaxis should be instituted as early as possible in patients awaiting surgery. Precautions are necessary for patients taking dual antiplatelet agents and receiving thromboembolic prophylaxis when considering regional anaesthesia for surgery. The decision to perform regional anaesthesia should be made on individual basis with full consideration given to all potential complications.

Future studies are necessary to determine the optimal peri-operative treatment strategies for patients on antiplatelet agents and on thromboembolic prophylaxis when they undergo hip fracture surgery.

Conflicts of interest Dr. Leung is the speaker for Synthes and has received research support from Synthes. None of the other authors has a real or perceived conflict of interest or a disclosure of any personal or financial support.

Open Access This article is distributed under the terms of the Creative Commons Attribution Noncommercial License which permits any noncommercial use, distribution, and reproduction in any medium, provided the original author(s) and source are credited.

\section{References}

1. Lu-Yao GL, Baron JA, Barrett JA, Fischer ES (1994) Treatment and survival among elderly Americans with hip fractures: a population-based study. Am J Public Health 84:1287

2. Magaziner J, Simonsick EM, Kashner TM et al (1990) Predictors of functional recovery one year following hospital discharge for hip fracture: a prospective study. J Gerontol 45:M101

3. Magaziner J, Hawkes W, Hebel JR et al (2000) Recovery from hip fracture in eight areas of function. J Gerontol A Biol Sci Med Sci 55A:M498-M507

4. Morris AH, Zuckerman JD (2002) National consensus conference on improving the continuum of care for patients with hip fracture. J Bone Joint Surg Am 84-A:670-674

5. Morrison RS, Chassin MR, Siu AL (1998) The medical consultant's role in caring for patients with hip fracture. Ann Intern Med 128:1010

6. Davis FM, Woolner DF, Frampton C et al (1987) Prospective, multicentre trial of mortality following general or spinal anaesthesia for hip fracture surgery in the elderly. Br J Anaesth 59:1080 
7. Bredahl C, Nyholm B, Hindsholm KB et al (1992) Mortality after hip fracture: results of operation within $12 \mathrm{~h}$ of admission. Injury 23:83

8. Rogers FB, Shackford SR, Keller MS (1995) Early fixation reduces morbidity and mortality in elderly patients with hip fractures from low-impact falls. J Trauma 39:261

9. Bottle A, Aylin P (2006) Mortality associated with delay in operation after hip fracture: observational study. BMJ 332:947

10. Shiga T, Wajima Z, Ohe Y (2008) Is operative delay associated with increased mortality of hip fracture patients? Systematic review, meta-analysis and meta-regression. Can J Anaesth 5:146

11. Anonymous (1994) Collaborative overview of randomized trials of anti-platelet therapy-III: reduction in venous thrombosis and pulmonary embolism by antiplatelet prophylaxis among surgical and medical patients. Antiplatelet Trialists' Collaboration. BMJ 308:235

12. Merritt JC, Bhatt DL (2004) The efficacy and safety of perioperative antiplatelet therapy. J Thromb Thrombolysis $17: 21-27$

13. Kaluza GL, Joseph J, Lee JR, Raizner ME, Raizner AE (2000) Catastrophic outcomes of noncardiac surgery soon after coronary stenting. J Am Coll Cardiol 35:1288-1294

14. Vicenzi MN, Ribitsch D, Luha O, Klein W, Metzler H (2001) Coronary artery stenting before noncardiac surgery: more threat than safety? Anaesthesiology 94:367-368

15. Reddy PR, Vaitkus PT (2005) Risks of noncardiac surgery after coronary stenting. Am J Cardiol 95:755-757

16. Brown MJ, Long TR, Brown DR, Wass CT (2006) Acute coronary syndrome and myocardial infarction after orthopaedic surgery in a patient with a recently placed drug-eluting stent. J Clin Anesth 18:537-540

17. Lecompte T, Hardy J-F (2006) Antiplatelet agents and perioperative bleeding. Can J Anaesth 53(6 Suppl):S103-S112

18. Fleisher LA, Beckman JA, Brown KA, Calkins H, Chaikof E, Fleishmann KE, Freeman WK, Froehlich JB, Kasper E, Kersten JR, Riegel B, Robb JF (2007) ACC/AHA 2007 Guidelines on perioperative cardiovascular evaluation and care for noncardiac surgery. A report of the American College of Cardiology/American Heart Association Task Force on Practice Guidelines (Writing Committee to Revise the 2002 Guidelines on Perioperative Cardiovascular Evaluation for Noncardiac Surgery). Circulation 116:e418e499

19. Collet JP, Montalescot G (2006) Premature withdrawal and alternative therapies to dual oral antiplatelet therapy. Eur Heart $\mathbf{J}$ Suppl 8(Suppl):G46-G52

20. Charbucinska KN, Godet G, Itani O, Fleron NJ, Bertrand M, Rienzo M, Coriat P (2006) Anticoagulation management for patients with drug-eluting stents undergoing vascular surgery. Anesth Analg 103:261-263

21. Albaladejo P, Marret E, Piriou V, Samama CM (2006) French Society of Anesthesiology and Intensive Care. Management of oral antiplatelet agents in patients with coronary stents: recommendations of a French Task Force. Ann Fr Anesth Reanim 25 (7):796-798
22. Chassot P-G, Delabays A, Spahn DR (2007) Perioperative antiplatelet therapy: the case for continuing therapy in patients at risk of myocardial infarction. Br J Anaesth 99:316-328

23. Broad L, Lee T, Conroy M, Bolsin S, Orford N, Black A, Birdsey G (2007) Successful management of patients with a drug-eluting coronary stent presenting for elective, non-cardiac surgery. Br J Anaesth 98:19-22

24. Brilakis ES, Banerjee S, Berger PB (2007) Perioperative management of patients with coronary stents. J Am Coll Cardiol 49:2145-2150

25. Geerts WH, Pineo GF, Heit JA et al (2004) Prevention of venous thromboembolism: the Seventh ACCP Conference of Antithrombotic and Thrombolytic Therapy. Chest 126:338S

26. Geerts WH, Bergqvist D, Pineo GF et al (2008) Prevention of venous thromboembolism: American College of Chest Physicians Evidence-Based Clinical Practice Guidelines (8th Edition). Chest 133:381S

27. Eriksson BI, Bauer KA, Lassen MR, Turpie AG (2001) Fondaparinux compared with enoxaparin for the prevention of venous thromboembolism after hip-fracture surgery. N Engl J Med 345:1298

28. Collins R, Scrimgeour A, Yusuf S, Peto R (1988) Reduction in fatal pulmonary embolism and venous thrombosis by perioperative administration of subcutaneous heparin: overview of results of randomized trials in general, orthopaedic and urologic surgery. N Engl J Med 318:1162

29. Handoll HH, Farrar MJ, McBirnie J et al (2002) Heparin, low molecular weight heparin and physical methods for preventing deep vein thrombosis and pulmonary embolism following surgery for hip fractures. Cochrane Database Syst Rev (4):CD000305

30. Eriksson BI, Dahl OE, Rosencher N et al (2007) Dabigatran etexilate versus enoxaparin for prevention of venous thromboembolism after total hip replacement: a randomized, double-blind, non-inferiority trial. Lancet 370:949

31. Kohrs R, Hoenemann CW, Feirer N, Durieux ME (1999) Bupivacaine inhibits whole blood coagulation in vitro. Reg Anesth Pain Med 24:326-330

32. Borg T, Modig J (1985) Potential anti-thrombotic effects of local anaesthetics due to their inhibition of platelet aggregation. Acta Anaesthesiol Scand 29:739-742

33. Horlocker TT, Wedel DJ, Benzon H, Brown DL, Enneking FK, Heit JA, Mulroy MF, Rosenquist RW, Rowlingson J, Tryloa M, Yuan CS (2003) Regional anesthesia in the anticoagulated patient: defining the risks (the second ASRA Consensus Conference on Neuraxial Anesthesia and Anticoagulation). Reg Anesth Pain Med 28:172-197

34. Douketis JD, Dentali F (2006) Managing anticoagulant and antiplatelet drugs in patients who are receiving neuraxial anesthesia and epidural analgesia: a practical guide for clinicians. Tech Reg Anesth Pain Manag 10:46-55

35. Vandermeulen EP, Van Aken H, Vermylen J (1994) Anticoagulants and spinal-epidural anesthesia. Anesth Analg 79:1165-1177

36. Nightingale SL (1998) From the food and drug administration. JAMA 279:346 